Australian Journal of

Crop Science

AJCS

AJCS 13(06):837-846 (2019)

ISSN:1835-2707

doi: 10.21475/ajcs.19.13.06.p1327

\title{
Selection for salinity tolerance in an international rice collection at vegetative stage
}

\author{
Leila Nayyeripasand ${ }^{1}$, Ghasem Ali Garosi ${ }^{1}$, Asadollah Ahmadikhah ${ }^{2 *}$ \\ ${ }^{1}$ Agricultural Biotechnology Department, Faculty of Agriculture, Imam Khomeini International University, Qazvin, Iran \\ ${ }^{2}$ Department of Plant Sciences and Biotechnology, Faculty of Life Sciences and Biotechnology, Shahid Beheshi \\ University, G.C. Velenjak, Tehran, Iran
}

*Corresponding author: a_ahmadikhah@sbu.ac.ir

\begin{abstract}
Water and soil salinity as the main abiotic stresses decrease crop yield and restrict the use of agricultural lands. In order to assess salt stress effect on seedling growth of rice and to select more tolerant rice genotypes, a factorial experiment was performed at two levels of $\mathrm{NaCl}$ namely non-stress (EC $1.2 \mathrm{dS} \mathrm{m}^{-1}$ ) and salt-stress $\left(E C 10 \mathrm{dS} \mathrm{m}^{-1}\right.$ ) in hydroponics with an international rice collection consisted of 155 varieties. Seven stress tolerance indices including STI, SSI, HM, RDI, SSPI, ATI and TOL were used to identify salt tolerant genotypes. The results of variance analysis showed that the effect of genotypes (G), Salt treatment $(T)$ and $G \times T$ interaction were significant for all investigated traits (except for the effect of genotypes on shoot length). Under salt stress most genotypes showed similar trend of salt response, i.e. reduction in all traits. The results also revealed that dry weight (DW) was less affected than fresh weight (FW), and the shoot weight (SW) was affected more than the root weight (RW), indicating that shoot growth is more sensitive than root growth to salt stress. The $\mathrm{Na}^{+}, \mathrm{K}^{+}$and $\mathrm{Na}^{+}: \mathrm{K}^{+}$ratio were increased more than $713 \%$, reduced $22 \%$ and increased more than $996 \%$ under salt stress, respectively. Four stress tolerance indices including MP, HM, GMP and STI showed highest correlation with each other and also with plant performance ( $Z$-scores) under both normal and stress conditions; thus each of these indices can be used as the suitable indicators for screening salt tolerant genotypes. Based on the results, genotypes \#84, \#30 and \#48 showed the highest performance and STI under salinity condition, so they have considerable potential to improve salt tolerance in rice breeding programs. In addition, genotypes \#178, $\# 198$ and \#6 with the lowest values of STI were found to be intolerant genotypes to salt stress.
\end{abstract}

Keywords: Rice, Salt stress, Salt tolerance indices, Vegetative stage.

Abbreviation: ANOVA_analysis of variance; ATI_abiotic tolerance CV_coefficient of variation; DW_dry weight; FW_fresh weight; HM_harmonic mean; RDI_relative drought index; RDW_root dry weight; RDW:SDW_root to shoot dry weight ratio; RFW_root fresh weight; RFW:SFW_root to shoot fresh weight ratio; RL:SL_root to shoot length ratio; RL_root length; SDW_shoot dry weight; SFW_ shoot fresh weight; SL_shoot length; SSI_stress susceptibility index; SSPI_stress susceptibility percentage index; STI_stress tolerance index; TOL_tolerance index.

\section{Introduction}

Rice (Oryza sative L.) as one of the most important cereal crops feeds more than $50 \%$ of the world population (Xu et al., 2016). Asian people are the largest consumer of rice because it is their major food. According the role of rice in dealing the indigence and malnourishment people and increasing world population, increased production of rice is necessary, particularly via genetic improvement of its productivity under non-stress and stress conditions.

Abiotic stresses are the most important limiting factors of agricultural production in all parts of the world. The improvement rice for tolerance and efficiency under abiotic stresses and development of resistant varieties in breeding programs are numerous important goals. One of the most important abiotic stresses is salinity. Salt stress decreases crop yield and restricts the efficient use of agricultural lands. It is estimated that of the 280 million hectares under agriculture crops, approximately $20 \%$ is saline (FAO 2008). Salinity is a major constraint for rice production due to sensitivity of rice at seedling and reproductive stages (Singh and Flowers, 2010). Rice is the most sensitive crop plant with a threshold of 3 $\mathrm{dSm}^{-1}$ for most cultivated varieties. Therefore, rice is classified as a salt sensitive crop, especially in the early stages of its growth (Kumar et al., 2013). Low osmotic potential of soil solution resulting in water stress causes salt stress, nutritional imbalance, specific ion effect and any combination of these factors (Evelin et al., 2009). Salt stress may cause membrane disorganization, generation of toxic metabolites, inhibition of photosynthesis, generation of reactive oxygen species (ROS) and attenuated nutrient acquisition leading to cell and whole plant death (Ashraf and Harris 2004; Chartzoulakis 2005; Sun 
et al., 2011). Salt tolerance in crop plants is a genetic and physiological complex trait and is controlled by several quantitative trait loci (Rozema and Flowers 2008). The plant's response to salinity stress is composed of two phases (Munns and Tester 2008). The first phase concerns the osmotic stress that is perceived immediately upon plant exposure to highly saline conditions. The second phase is manifested when high concentrations of toxic ions are built up over a longer period of time (Long et al., 2013).

It was established that in life cycle of plants, seed germination and early seedling growth are potentially the most sensitive and critical stages under abiotic stresses. Therefore, successful plant cultivation depends on the ability of seeds to germinate and survive under abiotic conditions (Foolad et al., 2003). Salinity stress, depending on severity and duration, causes significant changes in different physiological and metabolic processes, and ultimately decreases crop production (Gupta and Huang, 2014; James et al., 2011; Rahnama et al., 2010). Initially soil salinity represses plant growth in the form of osmotic stress which is then followed by ion toxicity (James et al., 2011; Rahnama et al., 2010). During the initial phases of salinity stress, water absorption capacity of root systems decreases and water loss from leaves is accelerated due to osmotic stress of high salt accumulation in soil and plants, and therefore salinity stress is also considered as hyperosmotic stress (Munns, 2005). Salt stress affects significantly early seedling stage of rice and reduces seedling vigor including root length (RL), shoot length (SL) and other seedling growth parameters (Hakim et al., 2014). Recently several reports have been devoted to the adverse effects of salinity stress on seedling growth in different plants such as marigold (Rawia Eid et al., 2011), catharanthus (Misra and Gupta, 2006), barley (Shabala et al., 2010; Zhu et al., 2017), maize (Cicek et al., 2002; Shan et al., 2013), wheat (Ahmed et al., 2010; Wu et al., 2015) and rice (Ibraheem et al., 2011; Roychoudhury et al., 2011; Hakim et al., 2014; Kumar et al., 2015; Shankar et al., 2016; Yeo et al., 2018).

Stress indices have been developed that may be more applicable to identify salinity tolerant varieties (Rezai and Saeidi, 2005). Rosielle and Hamblin (1981) proposed stress tolerance (TOL) as the differences in yield between the stress $(Y s)$ and non-stress (Yp) environments, and also defined mean productivity (MP) as the average yield of Ys and Yp. Fischer and Maurer (1978) proposed the stress susceptibility index (SSI). If the SSI amount becomes smaller, the level of stress tolerance is higher. High values of TOL and SSI indicate greater sensitivity to stress, however lower values of these indices would be desirable. Selection of better varieties based on TOL is useful for the modification of performance under stress conditions. Fernandez (1992) proposed a newer index (STI= stress tolerance index), which can be used to identify genotypes with high yield under both stress and non-stress conditions. Selection of tolerant varieties based on STI will be resulted in genotypes with higher stress tolerance and yield potential.

Three new indices including ATI (abbiotic-stress tolerance index), SSPI (stress susceptibility percentage index) and SNPI (stress non-stress production index) were proposed by Moosavi et al. (2008) to identify relatively tolerant (through ATI and SSPI) and resistant (through SNPI) genotypes under non-stress condition. According to them, ATI and SSPI are able to separate relative tolerant and non-tolerant genotypes better than previous indices proposed by others, and SNPI differentiates genotypes with high and stable yield at both stress and non-stress conditions. Fernandez (1992) divided studied genotypes into four groups based on their performance at stress and non-stress conditions: (Group A): genotypes with uniform superiority in both stress and nonstress conditions, (Group B): genotypes with favorably performance only at non-stress conditions, (Group C): genotypes with relatively higher performance only at stress conditions, and (Group D): genotypes with poor performance at both stress and non-stress conditions. According to Fernandez (1992) the best selection index should discriminate Group A from the other three groups. Three-dimensional plotting of yield at stress condition ( $Y s$ ), yield at non-stress condition ( $Y p$ ) and STI, displays the relationships between these three variables to discriminate genotypes of Group A from others.

This research was conducted out (i) to assess the effect of salt stress mediated by $\mathrm{NaCl}$ on rice vegetative growth and the salinity responses of an international rice collection consisted from 155 genotypes, and (ii) to select more tolerant rice varieties based on several salt tolerance indices. Comparison of these parameters in this research panel may be helpful in developing a better understanding and provide extra information on the mechanisms of salt tolerance.

\section{Results}

\section{Salt responses of the studied collection}

A total of 155 rice accessions, taken from the International Rice Research Institute (IRRI), were phenotypically evaluated under salt stress. The analysis of variance (ANOVA) showed that treatments (normal and saline) had significant or very significant differences for all the studied characteristics except for the shoot length (SL). There was a significant difference between genotypes (G) and GxT interaction for all the studied traits (Table 1).

Results showed that shoot length (SL), turgescence weight (TW), root length to shoot length ratio (RL:SL) and root dry weight to shoot dry weight ratio (RDW:SDW) at saline condition were not significantly changed compared to normal condition. But features such as root fresh weight (RFW), root fresh weight to root length ratio (RFW:RL), shoot sodium to shoot potassium (SNa:SK) and water content (WC) amounts, were increased under saline condition. But the other traits showed a significant decrease at salinity condition (Table 2).

The results of ANOVA for root length ( $R L$ ) indicated that the effects of genotypes, salt levels and interaction between them were significantly different $(P \leq 0.01)$. All rice genotypes had significant reduction in root length $(R L)$ under salt stress as compared to control condition. Furthermore, significant GXT interaction existed for RL (Table 1). At normal condition, RL had its highest values and salt stress strongly reduced the seedling's RL. Generally, genotype \#67 among all genotypes had least RL value under salt stress. In contrast, genotype \# 9 had the highest RL. 
The results of ANOVA for shoot fresh weight (SFW) indicated that the effects of genotypes, salt levels and interaction between them were highly significantly different $(P \leq 0.01)$. All rice genotypes had significant reduction in SFW (Table 1). Genotype \#178 among all genotypes had least SFW value at stress condition. In contrast, genotype \#30 had the highest SFW.

The results of ANOVA for RWC indicated that the effects of genotypes, salt levels and interaction between them were highly significantly different $(P \leq 0.01)$. All rice genotypes had significant reduction in RWC at stress condition as compared to control condition. Furthermore, significant GXT interaction existed for RWC and SDW (Table 1). Genotype \#178 among all genotypes had the least RWC value at two stress levels, genotype \#48 had the highest RWC, while for SDW, genotype\#6 had the least SDW value at two stress levels, and genotype \#195 had the highest SDW.

The results of ANOVA for SNa and SK indicated that the effects of genotypes, salt levels and interaction between them were very significantly different $(P \leq 0.01)$. All rice genotypes had significant reduction in shoot $\mathrm{Na}$ and $\mathrm{K}$ contents under stress condition as compared to control condition. Furthermore, significant GXT interaction existed for SNa and SK (Table 1). At normal condition, $\mathrm{SNa}$ had its least values, while salt stress strongly increased the seedling's SNa ( 713\%). In contrast, SK significantly reduced under salt stress $(-22.2 \%)$ and SNa: SK ratio was significantly increased ( 996\%). Generally, genotype \#140 among all genotypes had least SNa value at stress condition. In contrast, genotype \#84 had the highest SNa. Highest SK increase under salt stress was observed for genotypes \#3 (52.3\%), \#37 (32.4\%) and \#69 (24.1\%), followed by genotypes \#59 (19.2\%), \#48 (16.8\%) and \#78 (9.2\%).

\section{Correlations between seedlings traits}

The correlation coefficients between different traits under salinity stress are presented in Table 3 . As seen, the highest correlation (0.97) under stress condition was observed between TW and SFW. In contrast, the least correlations $(r=0.003)$ were found between RL and WC, and also between $\mathrm{RL}$ and $\mathrm{RNa}$ that they had non-significant correlations with most of other studied parameters under stress condition. A positive and significant correlation among RWC and RNa was identified. In addition, $\mathrm{SNa}$ had a positive and significant correlation with turgescence weight (TW).

\section{Comparing genotypes based on the salt-related indices}

In order to screening of genotypes under salt condition, stress indices based on Z-scores of genotypes under both normal and salt stress conditions were measured for calculating different sensitivity and tolerance indices. Salt stress consistently decreased the Z-score of genotypes under stress condition relative to normal condition. Results of different salt stress indices are presented in Table S2. The greater the TOL value, the larger was the reduction in Z-scores under stress condition and hence the higher was the salt sensitivity.

According to TOL index, genotypes \#206, \#48 and \#80 showed the highest TOL values at stress condition, and genotypes \#283 and \#145 showed the least TOL values. In the case of SSI parameter, genotypes \#178, \#198, \#61, \#144 and \#112 displayed the highest values and genotypes \#283 and \#120 displayed the least SSI values (data not shown).

According to ATI parameter, genotypes \#167, \#229, \#10 and $\# 169$ had the least values, whereas genotypes \#206, \#48 and $\# 80$ had the highest ATI values. In the case of SSPI, genotypes $\# 206$, \#48 and \#80 showed the highest values and the genotypes \#283, \#145 and \#120 showed the least SSPI values. The last two indices (ATI and SSPI) indicate the relative tolerance of genotypes to salt stress. ATI and SSPI rely on survival mechanisms under stress condition and they emphasize on stability of genotypes rather than high performance. These two indices have high positive correlation and both of them cannot separate group $C$ from group $A$. Based on HM index, the genotypes \#84, \#48 and \#30 showed the highest $\mathrm{HM}$ values and the genotypes with the lowest $\mathrm{HM}$ values were \#178, \#198. \#61 and \#6. Finally, based on STI, genotype \#84 followed by genotypes \#48 and \#30 were found to be salt tolerant genotypes, while genotypes \#178, \#198 and \#6 with the lowest values of STI were found to be intolerant genotypes to salt stress.

\section{Correlation analysis between salt-related indices}

The highest positive correlation ( $r=1.0$ ) was observed between TOL and SSPI and also between SSI and RDI at stress condition (Table 4). Zp was significantly and positively correlated with TOL, SSI, STI, HM, ATI, MP, GMP, STI and SSPI. Also, Zs was significantly and positively correlated with MP, GMP, STI and $\mathrm{RDI}$, indicating that these criteria were more effective in identifying high performance genotypes under salt conditions. This analysis were also negatively correlated SSI with HM, MP, GMP, STI and RDI. The results indicated that there were high positive and significant correlations among Zp and Zs with HM, MP, GMP and STI.

\section{Genotype selection by PCA analysis}

In order to evaluate and identify favorable genotypes, a principal component analysis (PCA) was conducted based on Zscores. As seen in Fig 1, the first two principal components (PC1 and PC2) of GGE analysis explained $\sim 100 \%$ of GGE sum of squares, so that 55.8 and $44.2 \%$ of total variation in data matrix of GGE, respectively, was explained by PC1 and PC2. Based on the biplot, it is possible to assess both mean performance and stability through it. The line passing through the biplot origin is called the average tester coordinate (ATC), which is defined by the average PC1 and PC2 scores of all environments (Yan and Kang 2003). The average performance of genotypes is estimated by projections of their markers on to the ATC horizontal axis. Thus, genotypes \#84 and \#30 had the highest average performance followed by \#48, and genotypes $\# 6$ and \#178 had the lowest average performance. Stability of each genotype is explored by its projection on to the ATC vertical axis. The smaller the absolute length of projection of a genotype, the more stable it is. Therefore, 
Table 1. Analysis of variance for studied traits of rice genotypes under control condition and salt stress.

\begin{tabular}{|c|c|c|c|c|c|c|c|c|c|c|c|c|c|c|c|c|c|c|}
\hline $\begin{array}{l}\text { Source of } \\
\text { variation }\end{array}$ & Df & SL & SFW & SFW:SL & $\mathrm{RL}$ & RFW & $R F W \cdot R L$ & TW & SDW & RDW & $R L: S L$ & $\begin{array}{c}\text { RFW:SF } \\
W\end{array}$ & $\begin{array}{c}\text { RDW:SD } \\
W\end{array}$ & $W C$ & BWC & $\mathrm{SNa}$ & 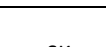 & \\
\hline & 1 & & 21651.22* & $298.56^{*}$ & $2304.66 *$ & $66014.85^{*}$ & $2307.27^{*}$ & & 1947.99* & $666.84^{*}$ & $16.99^{*}$ & & & $141.40^{*}$ & $2643.46^{*}$ & $60609.62^{*}$ & 6717.54* & $231.68^{*}$ \\
\hline Treatment & 15 & $\begin{array}{l}3.43^{\text {ns }} \\
23.99^{*}\end{array}$ & $*$ & $*$ & $*$ & $\begin{array}{c}* \\
11153.56 *\end{array}$ & $*$ & $\begin{array}{l}2064.13^{*} \\
9200.65 *\end{array}$ & $*$ & $\begin{array}{c}* \\
163.28^{*}\end{array}$ & $*$ & $0.465^{* *}$ & $0.804^{* *}$ & $*$ & $*$ & $*$ & $*$ & $*$ \\
\hline Genotype & $\begin{array}{c}4 \\
15\end{array}$ & $*$ & $7623.22^{* *}$ & $39.05^{* *}$ & $31.33^{* *}$ & $*$ & $147.01^{* *}$ & $\begin{array}{c}* \\
1384.63 *\end{array}$ & $140.58^{* *}$ & $*$ & $0.26^{* *}$ & $0.173^{* *}$ & $1.442^{* *}$ & $13.68^{* *}$ & $57.25^{* *}$ & $32.02 * *$ & $34.25^{* *}$ & $0.19 * *$ \\
\hline G*T & $\begin{array}{l}4 \\
62\end{array}$ & $4.52^{* *}$ & $1229.77^{* *}$ & $10.57^{* *}$ & $24.75^{* *}$ & $2936.09 * *$ & $110.36 * *$ & $*$ & $29.97 * *$ & $53.84^{* *}$ & $0.17^{* *}$ & $\begin{array}{l}0.055^{* *} \\
0.01413\end{array}$ & $0.599 * *$ & $7.86 * *$ & $48.99 * *$ & $29.64^{* *}$ & $37.42^{* *}$ & $0.18^{* *}$ \\
\hline $\begin{array}{l}\text { Error } \\
\mathrm{cV}\end{array}$ & 0 & $\begin{array}{l}1.18 \\
0.089\end{array}$ & $\begin{array}{c}345.20 \\
0.088\end{array}$ & $\begin{array}{l}2.67 \\
0.0933\end{array}$ & $\begin{array}{c}2.334 \\
0.171\end{array}$ & $\begin{array}{c}635.3974 \\
0.182\end{array}$ & $\begin{array}{c}16.10 \\
0.235\end{array}$ & $\begin{array}{c}426.01 \\
0.090\end{array}$ & $\begin{array}{l}8.52 \\
0.099\end{array}$ & $\begin{array}{l}9.43 \\
0.163\end{array}$ & $\begin{array}{l}0.02 \\
0.184\end{array}$ & $\begin{array}{c}8 \\
0.180\end{array}$ & $\begin{array}{c}0.10265 \\
0.186\end{array}$ & $\begin{array}{l}1.18 \\
0.013\end{array}$ & $\begin{array}{c}11.85 \\
0.038\end{array}$ & $\begin{array}{c}0.579 \\
0.062\end{array}$ & $\begin{array}{l}1.11 \\
0.051\end{array}$ & $\begin{array}{c}0.002 \\
0.064\end{array}$ \\
\hline
\end{tabular}

*: significant at the 0.05 level; **: highly significant at the 0.05 level; ns: not significant.

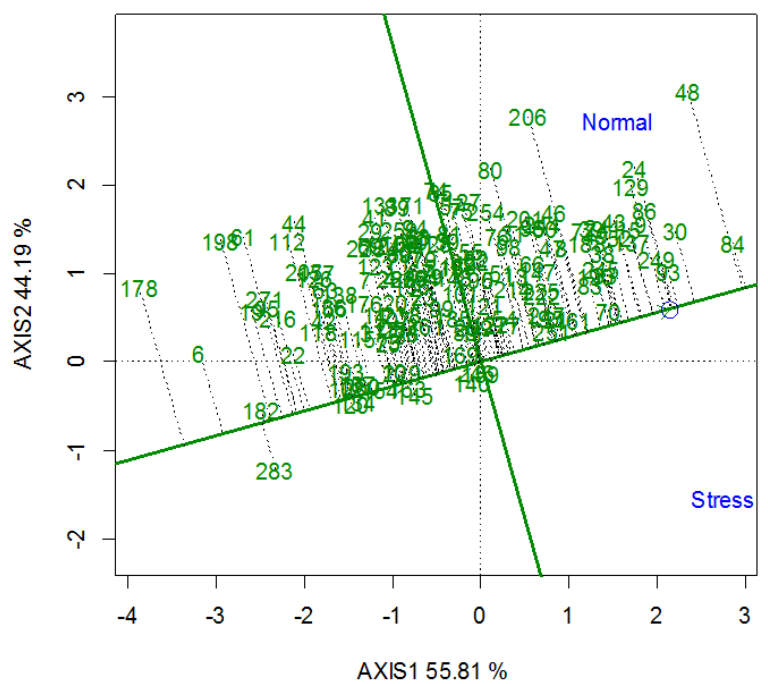

Fig 1. The graphical representation of principal component analysis (PCA) conducted with 155 rice genotypes under normal and salt stress conditions for detection of the contribution of two first components in total variation and for identification of more salt tolerant genotypes.

Table 2. Effect of salt stress on the studied traits

\begin{tabular}{|c|c|c|c|c|c|c|c|c|c|c|c|c|c|c|c|c|c|}
\hline $\begin{array}{l}\text { Stress } \\
\text { levels }\end{array}$ & $\begin{array}{l}\mathrm{SL} \\
(\mathrm{cm})\end{array}$ & $\begin{array}{l}\text { SFW } \\
\text { (mg) }\end{array}$ & $\begin{array}{l}\text { SFW:SL } \\
(\mathrm{mg})\end{array}$ & $\begin{array}{l}\mathrm{RL} \\
(\mathrm{cm}) \\
\end{array}$ & $\begin{array}{l}\text { RFW } \\
\text { (mg) }\end{array}$ & $\begin{array}{l}\text { RFW:RL } \\
\text { (mg) }\end{array}$ & $\begin{array}{l}\text { TW } \\
(\%) \\
\end{array}$ & $\begin{array}{l}\text { SDW } \\
\text { (mg) }\end{array}$ & $\begin{array}{l}\text { RDW } \\
(\mathrm{mg})\end{array}$ & $\begin{array}{l}\text { RL:SL } \\
(\mathrm{cm})\end{array}$ & $\begin{array}{l}\text { RFW:SFW } \\
\text { (mg) }\end{array}$ & $\begin{array}{l}\text { RDW:SDW } \\
\text { (mg) }\end{array}$ & $\begin{array}{l}\text { WC } \\
(\%)\end{array}$ & $\begin{array}{l}\text { RWC } \\
(\%)\end{array}$ & $\begin{array}{l}\mathrm{SNa} \\
(\mathrm{ppm})\end{array}$ & $\begin{array}{l}\text { SK } \\
\text { (ppm) }\end{array}$ & SNa:SK \\
\hline Control & $12.03^{a}$ & $215.54^{a}$ & $18.26^{\mathrm{a}}$ & $10.43^{\mathrm{a}}$ & $145.22^{\mathrm{a}}$ & $15.49^{b}$ & $231.94^{a}$ & $30.84^{a}$ & $19.53^{\mathrm{a}}$ & $0.88^{a}$ & $0.67^{a}$ & $1.76^{\mathrm{a}}$ & $85.52^{b}$ & $91.94^{a}$ & $3.49^{b}$ & $23.47^{a}$ & $0.15^{b}$ \\
\hline Stress & $12.20^{\mathrm{a}}$ & $206.19^{b}$ & $17.09^{b}$ & $7.38^{\mathrm{b}}$ & $130.29^{b}$ & $18.59^{\mathrm{a}}$ & $229.32^{\mathrm{a}}$ & $28.04^{\mathrm{b}}$ & $17.94^{b}$ & $0.62^{b}$ & $0.64^{b}$ & $1.70^{\mathrm{a}}$ & $86.28^{a}$ & $88.56^{\mathrm{b}}$ & $20.58^{\mathrm{a}}$ & $17.78^{b}$ & $1.21^{\mathrm{a}}$ \\
\hline
\end{tabular}

Note: means with similar letters are not significantly different at 0.05 level according to LSD test. 


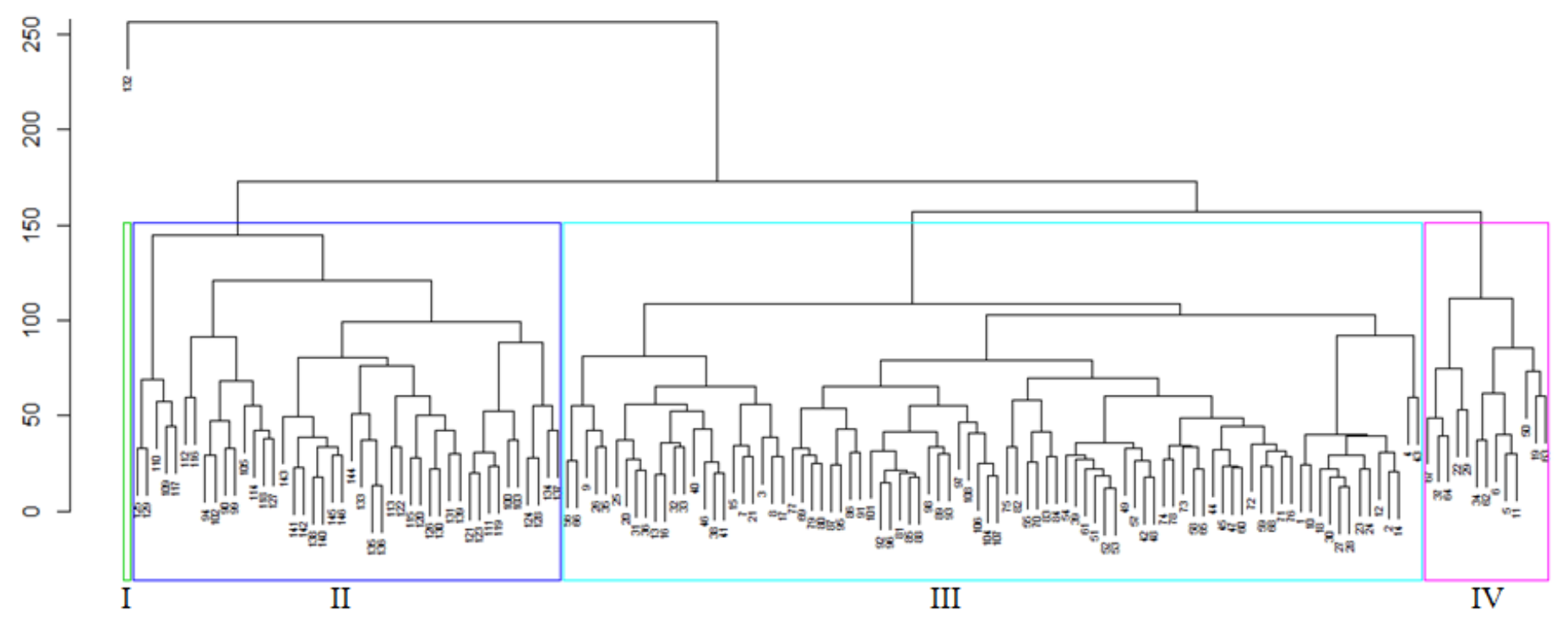

Fig 2. Dendrogram of the studied cultivars under salt stress based on UPGMA method. The 155 rice genotypes were placed in 4 clusters. The means of different traits of the genotypes in each cluster was given in Table 5.

Table 3. Correlation coefficients between different traits under salt stress

\begin{tabular}{|c|c|c|c|c|c|c|c|c|c|c|c|c|c|}
\hline & $S L$ & SFW & $R L$ & RFW & TW & SDW & RDW & WC & RWC & $\mathrm{SNa}$ & SK & $\mathrm{RNa}$ & RK \\
\hline SL & 1 & & & & & & & & & & & & \\
\hline SFW & $0.589^{* *}$ & 1 & & & & & & & & & & & \\
\hline $\mathrm{RL}$ & $0.121^{*}$ & $0.183^{*}$ & 1 & & & & & & & & & & \\
\hline RFW & $0.171^{*}$ & $0.459^{* *}$ & $0.254^{* *}$ & 1 & & & & & & & & & \\
\hline TW & $0.587^{* *}$ & $0.968^{* *}$ & $0.164^{*}$ & $0.430^{* *}$ & 1 & & & & & & & & \\
\hline SDW & $0.515^{* *}$ & $0.760^{* *}$ & $0.172^{*}$ & $0.323^{* *}$ & $0.763^{* *}$ & 1 & & & & & & & \\
\hline RDW & $0.203^{* *}$ & $0.399^{* *}$ & $0.235^{* *}$ & $0.813^{* *}$ & $0.404^{* *}$ & $0.404^{* *}$ & 1 & & & & & & \\
\hline WC & 0.061 & $0.301^{* *}$ & 0.017 & $0.196^{*}$ & $0.246^{* *}$ & $-0.367^{* *}$ & -0.007 & 1 & & & & & \\
\hline RWC & 0.055 & $0.185^{*}$ & 0.081 & $0.117^{*}$ & -0.062 & -0.007 & -0.014 & $0.309^{* *}$ & 1 & & & & \\
\hline $\mathrm{SNa}$ & $0.158^{*}$ & $0.217^{*}$ & $0.149^{*}$ & $0.147^{*}$ & $0.231^{* *}$ & $0.163^{*}$ & $0.125^{*}$ & 0.091 & -0.050 & 1 & & & \\
\hline SK & -0.037 & -0.068 & -0.070 & -0.031 & $-0.098^{*}$ & $-0.102^{*}$ & -0.087 & 0.066 & $0.107^{*}$ & $-0.106^{*}$ & 1 & & \\
\hline $\mathrm{RNa}$ & -0.081 & -0.024 & -0.017 & $0.102^{*}$ & -0.054 & $-0.132^{*}$ & 0.003 & $0.183^{*}$ & $0.131^{*}$ & $0.115^{*}$ & 0.084 & 1 & \\
\hline RK & -0.070 & -0.042 & $-0.098^{*}$ & $0.198^{*}$ & -0.076 & -0.066 & 0.088 & 0.066 & $0.147^{*}$ & 0.025 & $0.101^{*}$ & $0.399^{*}$ & 1 \\
\hline
\end{tabular}




\begin{tabular}{|c|c|c|c|c|c|c|c|c|c|c|c|}
\hline & $Z p$ & Zs & SSI & TOL & MP & GMP & $\mathrm{HM}$ & STI & RDI & ATI & SSPI \\
\hline$Z p$ & 1 & & & & & & & & & & \\
\hline Zs & $0.646 * *$ & 1 & & & & & & & & & \\
\hline \multirow[t]{2}{*}{ SSI } & $0.271^{* *}$ & - & 1 & & & & & & & & \\
\hline & & $0.487^{* *}$ & & & & & & & & & \\
\hline \multirow[t]{2}{*}{ TOL } & $0.587 * *$ & - & $0.861^{* *}$ & 1 & & & & & & & \\
\hline & & $0.239 * *$ & & & & & & & & & \\
\hline MP & $0.924 * *$ & $0.889 * *$ & -0.081 & $0.232^{* *}$ & $1 \quad$ ** & & & & & & \\
\hline GMP & $0.875^{* *}$ & $0.930 * *$ & $-0.178^{*}$ & 0.127 & $0.991^{* *}$ & 1 & & & & & \\
\hline $\mathrm{HM}$ & $0.832 * *$ & $0.955^{* *}$ & $-0.240^{* *}$ & 0.045 & $0.978_{* *}^{* *}$ & $0.996^{* * *}$ & 1 & & & & \\
\hline STI & $0.876 * *$ & $0.912 * *$ & -0.146 & 0.146 & $0.983^{* *}$ & $0.978^{* *}$ & $0.973^{* *}$ & 1 & & & \\
\hline \multirow[t]{2}{*}{$\mathrm{RDI}$} & - & $0.487 * *$ & $-1.000^{* *}$ & $-0.861^{* *}$ & 0.081 & $0.178^{*}$ & $0.240^{* *}$ & 0.146 & 1 & & \\
\hline & $0.271^{* *}$ & & & & & & & & & & \\
\hline \multirow[t]{2}{*}{ ATI } & $0.449 * *$ & - & $0.798^{* *}$ & $0.987^{* *}$ & 0.096 & -0.012 & -0.095 & 0.017 & - $\quad$ ** & 1 & . \\
\hline & & $0.297 * *$ & & & & & & & $0.798^{* *}$ & & \\
\hline \multirow[t]{2}{*}{ SSPI } & $0.587^{* *}$ & - & $0.861^{* *}$ & $1.000^{* *}$ & $0.232^{* *}$ & 0.127 & 0.045 & 0.146 & $-\quad * *$ & $0.987^{* *}$ & 1 \\
\hline & & $0.239 * *$ & & & & & & & $0.861^{* *}$ & & \\
\hline
\end{tabular}

**: Correlation is significant at the 0.01 level. *: Correlation is significant at the 0.05 level. $\mathrm{Zp}$ : performance at control condition ( $\left.2 \mathrm{dS} \mathrm{m}^{-1}\right)$; Zs: performance at salt stress condition (10 dS $\mathrm{m}^{-1}$ ).

Table 5. The means of clusters for different traits under salt stress condition

\begin{tabular}{|c|c|c|c|c|}
\hline Trait & Cluster 1 & Cluster 2 & Cluster 3 & Cluster 4 \\
\hline SL & 21.59 & 12.45 & 11.77 & 13.66 \\
\hline SFW & 321.86 & 205.58 & 196.39 & 264.02 \\
\hline SDW & 35.77 & 28.41 & 26.67 & 35.18 \\
\hline $\mathrm{RL}$ & 7.59 & 7.35 & 7.29 & 8.18 \\
\hline $\mathrm{RL} / \mathrm{SL}$ & 0.35 & 0.60 & 0.64 & 0.60 \\
\hline RFW & 112.6 & 134.11 & 117.36 & 198.61 \\
\hline RDW & 21.13 & 18.25 & 16.16 & 26.87 \\
\hline TW & 394.93 & 229.21 & 217.63 & 293.15 \\
\hline WC & 88.84 & 85.97 & 86.36 & 86.60 \\
\hline RWC & 79.58 & 88.09 & 88.93 & 88.94 \\
\hline $\mathrm{SNa}$ & 22.80 & 19.02 & 20.77 & 24.12 \\
\hline SK & 14.21 & 17.96 & 17.83 & 16.98 \\
\hline SNa:SK & 1.60 & 1.11 & 1.21 & 1.45 \\
\hline $\mathrm{RNa}$ & 14.25 & 20.84 & 22.47 & 21.19 \\
\hline RK & 2.83 & 6.47 & 6.80 & 7.90 \\
\hline RNa:RK & 5.04 & 3.50 & 3.70 & 3.69 \\
\hline
\end{tabular}


genotypes such as \#84 and \#30 were the most stable genotypes, and genotype \#178 were the least stable one. Altogether, considering both mean and stability performance, genotypes \#30 and \#84 followed by \#48 could be regarded as most tolerant and hence the most favorable genotypes.

\section{Cluster analysis}

Cluster analysis was performed using $\mathrm{K}-$ means clustering. The Euclidean distance was calculated based on morphological data and a UPGMA dendrogram was produced using the dissimilarity matrix for 155 rice genotypes under salt stress condition. The studied rice genotypes were grouped into 4 clusters based on within sum of squares (wss) parameter (Fig 2 ). Cluster \#1 comprised of only one genotype and clusters \#2, \#3 and \#4 contained 44, 97 and 13 genotypes, respectively. The single genotype in cluster 1 showed higher values of SL $(21.59 \mathrm{~cm})$, SFW (321.86 mg), TW (394.93 mg), WC (88.84\%), SNa (22.8 ppm), SNa:SK (1.6) and RNa:RK (5.04). The 2nd cluster composed of 44 genotypes had the highest value of SK (17.96 ppm) (Table 5). The members of the 3rd cluster were specified by higher values of RL:SL (0.64), RWC (88.93\%) and RNa (22.47 ppm). Finally, $4^{\text {th }}$ cluster had higher values of SDW (35.18 mg), RL (8.18 mm), RFW (198.61 mg), RDW (26.87), RWC (88.94\%), SNa (24.12 ppm) and RK (7.90 ppm) (Table 5).

\section{Discussion}

Due to the variation in sensitivity to salinity during the life cycle, evaluation of salinity tolerance in rice is complex (Waziri et al., 2016). When subjected to salt stress, rice plants had very different reactions depending on the characteristics of each genotype. Different rice varieties have varied levels of salinity tolerance at different growth stages (Hoang et al., 2016). Rice is comparatively tolerant to salinity stress during germination, active tillering, and towards maturity, but is sensitive during early seedling and reproductive stages (Heenan et al., 1988; Zeng et al., 2001). Moreover, salinity tolerance at the seedling and reproductive stages are only weakly, if at all, associated (Lafitte et al., 2004). Although plants' sensitivity to salinity is higher during early seedling stage and reproductive stage, crops need to maintain functions at all stages of their life cycle to increase their ability to maintain yield under high salinity (Negrão et al., 2017). For instance, yield can be reduced during the vegetative stage by affecting parameters such as tiller number per plant in cereals such as rice (Zeng and Shannon, 2000). In some cases, it has been reported that salinity tolerance at the seedling stage is independent of salinity tolerance at flowering/reproductive stage (Jena and Mackill 2008), for example, CN499-160-13-6 genotype has been confirmed as susceptible at seedling stage, but tolerant at the flowering stage (Gorantla et al., 2005).

As emphasized in several researches, genetic diversity is one of the important decisive factors for the selection of given genotypes in breeding programs (Temnykh et al., 2001; Ahmadikhah et al., 2008; Huang et al., 2010; Yang et al., 2014). The presence of adequate variation among rice genotypes in the present research was confirmed by PCA. The first two principal components accounted for $100 \%$ of the total variation at stress condition, so that first and second PCs contributed to $58.2 \%$ and $42.8 \%$ of the observed variation at stress condition. In a study by Kumar et al. (2015), 52\% and $14 \%$ of the total variation among 220 rice genotypes were distinguished using PCA. Similarly, Chunthaburee et al. (2016) indicated that under salt stress condition the first two components contributed $72.04 \%$ of the total variability among rice genotypes. The 155 rice genotypes in this study were clustered into 4 groups under stress condition. Cluster analysis recognized genotypes \#30 and \#84 with the highest performance under stress condition, indicating that these genotypes have a significant superiority over other genotypes. Majority of the studied rice genotypes had significant reduction in root length (RL) at stress condition. Reduction in $\mathrm{RL}$ due to water deficit caused by salinity was reported in several experiments. Similar results like decrement in root length (RL) with increment of osmotic stress were obtained in seven wheat cultivars by Jajarmi et al. (2009). Assessment of the fresh and dry weight values of roots (RFW and RDW) and shoots (SFW and SDW) showed that seedling growth was reduced by salinity stress, but dry weight was less affected than fresh weight. Salt stress affects significantly early seedling stage of rice and reduces seedling vigor including shoot dry weight (SDW) and root dry weight (RDW) (Hakim et al., 2014) and other seedling growth parameters. Based on these results we could conclude that decline in the water potential gradient between seeds and their surrounding media negatively affect the germination of seed and subsequent of events in seedling growth and development.

Two important characteristics calculated in the present study were ratios of SFW:SL and RFW:RL, so that the earlier was significantly decreased, but the latter was significantly increased under salt stress. These two ratios show density of shoot and root under given conditions. Normally, any stress reduces the cell elongation, and hence the length of tissues under study is shortened (Mohammadkhani and Heidari, 2008; Shalhevet, 1995; Wenkert et al., 1978), but it may be specific genotypes which don't follow this general rule, and hence we can consider such genotypes as stress tolerant. In this basis, cultivar \#169 showed increased SL and SFW:SL ratio, and cultivar \#283 showed increased RL and RFW:RL ratio, and perhaps they represent some aspects of salinity tolerance.

One of the most detrimental effects of salinity stress is the accumulation of $\mathrm{Na}^{+}$and $\mathrm{Cl}^{-}$ions in tissues of plants exposed to high $\mathrm{NaCl}$ concentrations. As expected, $\mathrm{Na}^{+}$accumulation under salt stress was significantly higher than that of normal condition ( 713\%), and $\mathrm{K}^{+}$accumulation was reduced significantly under salt stress (-22\%). As well documented, entry of both $\mathrm{Na}^{+}$and $\mathrm{Cl}^{-}$into the cells causes severe ion imbalance and excess uptake might cause significant physiological disorder (James et al., 2011). Again as expected, $\mathrm{Na}^{+}: \mathrm{K}^{+}$ratio was increased under salt stress ( 996\%). High $\mathrm{Na}^{+}$ accumulation inhibits uptake of $\mathrm{K}^{+}$ions which is an essential element for growth and development that results into lower productivity and may even lead to death of cell, tissue and whole plant (James et al., 2011).

Based on STI, genotype \#84 followed by genotypes \#48 and \#30 were found to be salt tolerant genotypes, while genotypes $\# 178, \# 198$ and \#6 with the lowest values of STI were found to 
be intolerant genotypes to salt stress. The higher the STI value the greater salt tolerance was. The main and best advantage of STI index is its ability to discriminate group A from other groups (Fernandez, 1992).

To identify favorable genotypes, a biplot PCA analysis was conducted and according to the analysis ideal genotypes are those that have large PC1 scores (high performance) and small (absolute) PC2 scores (high stability) (Yan and Rajcan 2002) Considering both mean and stability performance, two genotypes \#84 and \#30 had the highest average performance (PC1) and a relatively low PC2, and hence they could be regarded as most tolerant genotypes.

\section{Materials and methods}

\section{Plant materials}

A total of 155 rice accessions (Table S1) were selected from a larger panel of 283 rice diverse accessions received from the Chang Genetic Resources Center of International Rice Research Institute (IRRI, Philippines), and used in this study. The experiment was conducted in Shahid Beheshti University, Tehran, Iran. These accessions were cultured in early April (2017).

\section{Experimental design}

The experiment was done in a completely randomized design (CRD) with three replications under 2 conditions including normal and salt stress treatments. Plant materials were evaluated in a factorial experiment (155 genotypes and two levels of salt stress induced by $\mathrm{NaCl}$ ).

\section{Conduction of study}

Before starting the salt treatment, seeds were surfacesterilized with solution of $10 \%$ sodium hypochlorite for 10 minutes with gentle shaking at room temperature. After the sterilization, the seeds were washed three times with autoclaved distilled water. Then, for germination the seeds of each variety were put in paper towels, the papers were transferred to plastic bags, wet with $10 \mathrm{ml}$ of a nutrient solution and then were transferred to an incubator at $28^{\circ} \mathrm{C}$. After three days, they were transferred to a growth chamber at $25^{\circ} \mathrm{C}, 60 \%$ relative humidity under $16 / 8-\mathrm{hr}$ day light photoperiod.

\section{Treatments}

The control non-stress treatment contained only Yoshida solution (EC $1.2 \mathrm{dS} \mathrm{m}^{-1}$ ), while salt stress treatment was induced by adding appropriate amount of $\mathrm{NaCl}$ (EC $10 \mathrm{dS} \mathrm{m}^{-1}$ ) to the Yoshida solution in hydroponic status.

\section{Traits measured}

For evaluating the given traits after normal and salt treatments (14 days after transfer to growth chamber), ten seedlings from each replicate were randomly selected and separated to root and shoot sections. The growth of seedling sections including root length (RL), shoot length (SL), root to shoot length ratio $(R L: S L)$, root fresh weight (RFW), shoot fresh weight (SFW), root to shoot fresh weight ratio (RFW:SFW) was measured. Furthermore, fresh roots and shoots were oven-dried at $80^{\circ} \mathrm{C}$ for $24 \mathrm{~h}$. After that root dry weight (RDW), shoot dry weight (SDW) were also measured. Turgescence weight (TW) was measured $24 \mathrm{~h}$ after floating the shoots in distilled water. Also, the oven-dried seedling shoots were weighted to calculate water content (WC) and relative water content (RWC). Furthermore, shoot $\mathrm{Na}^{+}(\mathrm{SNa})$ and shoot $\mathrm{K}^{+}$(SK) contents were measured by flame photometry and expressed in ppm.

\section{Statistical analysis}

To determine differences among genotypes (G), salt treatment levels $(T)$ and $G \times T$ interaction, the phenotypic data were analyzed by using general linear model (GLM) of the SPSS V.19 software (Gray and Kinnear 2002). Differences between means were compared using LSD test and Duncan multiple range tests at the $5 \%$ level of significance ( $p \leq 0.5)$.

Simple correlation coefficients between morphological traits were estimated to determine the association between traits using Pearson's correlation coefficient. The recorded data for each trait was initially standardized, obtaining the $Z$ scores by means of the expression $Z=(Y-\hat{Y}) / S$, where $Z$ is the value of the standardized variable corresponding to the respective trait, $\mathrm{Y}$ is observation of trait, $\hat{Y}$ is the overall mean of trait in three replications and $S$ is phenotypic standard deviation of given trait. A constant was added to the $Z$ values to avoid the occurrence of negative values.

A principal component analysis (PCA) was conducted to determine the contribution of different components in total variation, and also to identify more salt tolerant genotypes. A cluster analysis based on UPGMA method also was conducted to group the studied genotypes by using their performance for different traits under salt condition.

The different aspects of response of the genotypes to salt stress were investigated using different indices including stress susceptibility index (SSI), stress tolerance index (STI), tolerance index (TOL) etc. which their formula are represented here:

Stress Susceptibility Index (SSI) $=(1-(\mathrm{Ys} / \mathrm{Yp})) /\left(1-\left(\hat{\mathrm{Y}}_{\mathrm{s}} / \hat{\mathrm{Y} p} \mathrm{p}\right)\right)$

(Fisher and Maurer, 1978)

Stress Tolerance Index $(\mathrm{STI})=(\mathrm{Yp} * \mathrm{Y} s) /(\hat{\mathrm{Y} p})^{2} \quad$ (Fernandez, 1992)

Tolerance Index (TOL) $=Y p-Y s \quad$ (Rosielle and Hambline, 1981) Mean Productivity (MP) $=(Y p+Y s) / 2$

(Rosielle and Hambline, 1981)

Geometric Mean Productivity (GMP)=VYp.Ys (Fernandez, 1992)

Stress Intensity (SI)=1-(Ŷs/Ŷp) (Fisher and Maurer, 1978)

Abiotic-stress tolerance index $(\mathrm{ATI})=(\mathrm{Yp}-\mathrm{Ys}) /(\hat{\mathrm{Y} p} / \hat{\mathrm{Y}} \mathrm{s}) \times(\mathrm{V} \mathrm{Yp}-\mathrm{Ys})$ (Moosavi et al. 2008)

Stress susceptibility percentage index $(S S P I)=(Y p-s) / 2(\hat{Y} p)) \times 100$

(Moosavi et al. 2008)

Relative drought index $(R D I)=(\mathrm{Ys} / \mathrm{Yp}) /(\hat{\mathrm{Y}} \mathrm{s} / \hat{\mathrm{Y} p})$

Fischer and Wood (1979)

In these equations $Y s, Y p, \hat{Y} s$ and $\hat{Y} p$ represent performance of each genotype under stress condition, performance of each genotype under non-stress condition, performance mean under stress and non-stress conditions for all genotypes, 
respectively.

\section{Conclusion}

The results of the present research clearly suggested that salt stress greatly influences seedling growth characteristics of the rice genotypes. The results showed that a lot of variation was observed among studied genotypes for most of the evaluated traits, indicating that selection in this rice collection would be useful in breeding programs for salt tolerance. To identify salt tolerant genotypes, several stress indices were used. Among different indices, STI can be used as the most suitable indicator for screening salt tolerant genotypes with high performance under both stress and non-stress conditions. In addition, PCA analysis based on two PCs is a suitable method to identify superior stable genotypes under both stress and non-stress conditions. Based on the results of this research, it can be concluded that genotypes \#84 and \#30 followed by \#48 with the highest performance under normal and salinity conditions, had a significant superiority over other genotypes. They were also desirable in terms of STI and HM, so they have considerable potential to improve salt tolerance in rice breeding programs. On the other hand, genotypes \#178 and \#6 with the lowest values of STI were found to be intolerant genotypes to salt stress

\section{Acknowledgments}

This work was conducted in Biotechnology laboratory, Department of Plant Sciences and Biotechnology, Shahid Beheshti University, Iran. We thank Iran National Biotechnology Council (INBC) for partial financial support of the work. In addition we express grateful thanks to International Rice Research Institute (IRRI) in Philippines for providing the seeds of rice cultivars.

\section{References}

Ahmadikhah A, Alishah O, Nasrollanejad S (2008) Quantitative studies for investigating variation and its effect on heterosis of rice. Int J Plant Prod. 2(4): 297-307.

Ahmadikhah A, Shojaeian H, Pahlavani MH, Nayyeripasand L (2014) Identification of salt tolerant mutants in rice and their fingerprinting using ISSR markers. Modern Genet J. 9(3): 299312.

Ahmed BO, Inoue M, Moritani S (2010) Effect of saline water irrigation and manure application on the available water content, soil salinity, and growth of wheat. Agric Water Manage. 97(1): 165-170.

Ashraf MPJC, Harris PJC (2004). Potential biochemical indicators of salinity tolerance in plants. Plant Sci. 166(1): 3-16.

Chartzoulakis KS (2005). Salinity and olive: growth, salt tolerance, photosynthesis and yield. Agric Water Manage. 78(1-2): 108121.

Chunthaburee S, Dongsansuk A, Sanitchon J, Pattanagul W, Theerakulpisut P (2016) Physiological and biochemical parameters for evaluation and clustering of rice cultivars differing in salt tolerance at seedling stage. Saudi J Biol Sci. 23(4): 467-477.
Cicek N, Cakirlar H (2002) The effect of salinity on some physiological parameters in two maize cultivars. Bulg J Plant Physi. 28(1-2): 66-74.

Evelin H, Kapoor R, Giri B (2009) Arbuscular mycorrhizal fungi in alleviation of salt stress: a review. Ann Bot. 104(7): 1263-1280.

FAO (2008) Food and agriculture organisation of the United Nations. Retrieved on 15 Jan 2018.

Farshadfar E, Ghannadha M, Zahravi M, Sutka J (2001) Genetic analysis of drought tolerance in wheat. Plant Breed. 114: 542544.

Fernandez GCJ (1992) Effective selection criteria for assessing plant stress tolerance. In. C. G. Kuo, ed. Adaptation of Vegetables and other Food Crops in Temperature and Water Stress. Publication Number 93-410, pp. 257-270, Asian Vegetable Research Development Center, Shanhua, Taiwan.

Fischer RA, Maurer R (1978) Drought resistance in spring wheat cultivars. I. Grain yield responses. Aust J Agric Res. 29: 897-912.

Fischer RA, Wood JT (1979) Drought resistance in spring wheat cultivars III. Yield association with morphological traits. Aust J Agric Res. 30: 10011020.

Foolad MR, Subbiah P, Kramer C, Hargrave G, Lin GY (2003) Genetic relationships among cold, salt and drought tolerance during seed germination in an interspecific cross of tomato. Euphytica. 130(2): 199-206.

Franco JA, Bañón S, Vicente MJ, Miralles J, Martínez-Sánchez JJ (2011) Root development in horticultural plants grown under abiotic stress conditions- a review. J Hort Sci Biotechnol. 86(6): 543-556.

Gorantla M, Babu PR, Reddy, VBL, Feltus FA, Paterson, AH, Reddy $A R$ (2005) Functional genomics of drought stress response in rice: Transcript mapping of annotated unigenes of an indica rice (Oryza sativa L. cv. Nagina 22). Curr Sci. 89: 496-514.

Gray CD, Kinnear PR (2012) IBM SPSS statistics 19 made simple. Psychology Press.

Gupta B, Huang B (2014) Mechanism of Salinity Tolerance in Plants: Physiological, Biochemical, and Molecular Characterization. Int J Genomics. 2014.

Hakim MA, Juraimi AS, Hanafi MM, Ismail MR, Rafii MY, Islam MM, Selamat A (2014) The effect of salinity on growth, ion accumulation and yield of rice varieties. J Anim Plant Sci. 24(3): 874-885.

Heenan DP, Lewin LG; McCaffery DW (1988) Salinity tolerance in rice varieties at different growth stages. Aust J Exp Agric. 28: 343-349.

Hoang TML, Tran TN, Nguyen TKT, Williams B, Wurm P, Bellairs S, Mundree $S$ (2016) Improvement of salinity stress tolerance in rice: challenges and opportunities. Agron. 6(4): 54.

Huang X, Sang T, Zhao Q, Feng Q, Zhao Y, Li C, Fan D (2010) Genome-wide association studies of 14 agronomic traits in rice landraces. Nat Genet. 42(11): 961-967.

Ibraheem O, Dealtry G, Roux S, Bradley G (2011) The Effect of Drought and Salinity on the Expressional Levels of Sucrose Transporters in Rice ('Oryza sativa' Nipponbare) Cultivar Plants. Plant Omics. 4(2): 68.

Jafari A, Paknejad F, Al-Ahmadi MJ (2009) Evaluation of selection indices for drought tolerance of corn (Zea mays L.) hybrids. Inter J Plant Prod. 3(4): 33-38.

Jajarmi V (2009) Effect of water stress on germination indices in seven wheat cultivar. World Acad Sci Eng Technol. 49: 105-106. 
James RA, Blake C, Byrt CS, Munns R (2011) Major genes for $\mathrm{Na}^{+}$ exclusion, Nax1 and Nax2 (wheat HKT1;4 and HKT1;5), decrease $\mathrm{Na}^{+}$accumulation in bread wheat leaves under saline and waterlogged conditions. J Exp Bot. 62(8): 2939-2947.

Jena KK, MacKill DJ (2008) Molecular markers and their use in marker-assisted selection in rice. Crop Sci. 48: 1266-1276.

Kumar V, Singh A, Mithra SA, Krishnamurthy SL, Parida SK, Jain S, Khurana JP (2015) Genome-wide association mapping of salinity tolerance in rice (Oryza sativa). DNA Res. 22(2): 133-145.

Lafitte HR, Ismail AM, Bennett J (2004) Abiotic stress tolerance in rice for Asia: Progress and future. In Proceedings of the 4th International Crop Science Congress, Brisbane, Australia, 26 September-1 October 2004.

Long NV, Dolstra O, Malosetti M, Kilian B, Graner A, Visser RG, van der Linden CG (2013) Association mapping of salt tolerance in barley (Hordeum vulgare L.). Theor Appl Genet. 126(9): 23352351

Mehrabi P, Homayoun H, Daliri MS (2011) Study of Drought tolerance of corn genotypes using STI index. Middle-East J Sci Res. 9(1): 68-70.

Misra N, Gupta AK (2006) Effect of salinity and different nitrogen sources on the activity of antioxidant enzymes and indole alkaloid content in Catharanthus roseus seedlings. J Plant Physi. 163(1): 11-18.

Mohammadkhani N, Heidari R (2008) Water stress induced by polyethylene glycol 6000 and sodium chloride in two maize cultivars. Pak J Biol Sci. 11(1): 92-97.

Moosavi SS, Yazdi Samadi B, Naghavi MR, Zali AA, Dashti H, Pourshahbazi A (2008) Introduction of new indices to identify relative drought tolerance and resistance in wheat genotypes. Desert. 12(2): 165-178.

Munns R (2005) Genes and salt tolerance: bringing them together. New Phytol. 167(3): 645-663.

Munns R, Tester M (2008) Mechanisms of salinity tolerance. Annu Rev Plant Biol. 59: 651-681.

Negrão S, Schmöckel SM, Tester M (2017) Evaluating physiological responses of plants to salinity stress. Ann Bot. 119(1): 1-11.

Rahnama A, James RA, Poustini K, Munns R (2010) Stomatal conductance as a screen for osmotic stress tolerance in durum wheat growing in saline soil. Funct Plant Biol. 37(3): 255-263.

Rawia Eid A, Taha LS, Ibrahiem SMM (2011) Alleviation of adverse effects of salinity on growth, and chemical constituents of marigold plants by using glutathione and ascorbate. J Appl Sci Res. 7: 714-721.

Rezai AM, Saeidi G (2005) Genetic analysis of salt tolerance in early growth stages of rapeseed (Brassica napus L.) genotypes. Indian J Genet PI Br. 65(4): 269-273.

Rosielle AA, Hamblin J (1981) Theoretical aspects of selection for yield in stress and non-stress environment. Crop Sci. 21: 943946.

Roychoudhury A, Basu S, Sengupta DN (2011) Amelioration of salinity stress by exogenously applied spermidine or spermine in three varieties of indica rice differing in their level of salt tolerance. J Plant Physi. 168(4): 317-328.

Rozema J, Flowers T (2008) Ecology: crops for a salinized world. Science. 322(5907): 1478-1480.
Shabala S, Shabala S, Cuin TA, Pang J, Percey W, Chen Z, Wegner LH (2010) Xylem ionic relations and salinity tolerance in barley. Plant J. 61(5): 839-853.

Shalhevet J, Huck MG, Schroeder BP (1995) Root and shoot growth responses to salinity in maize and soybean. Agron J. 87(3): 512516.

Shan X, Li Y, Jiang Y, Jiang Z, Hao W, Yuan Y (2013) Transcriptome profile analysis of maize seedlings in response to high-salinity, drought and cold stresses by deep sequencing. Plant Mol Biol Rep. 31(6): 1485-1491.

Shankar R, Bhattacharjee A, Jain M (2016) Transcriptome analysis in different rice cultivars provides novel insights into desiccation and salinity stress responses. Sci Rep-UK. 6: 23719.

Singh RK, Flowers TJ (2010) The physiology and molecular biology of the effects of salinity on rice. In: Pessarakli M (ed) Handbook of Plant and Crop Stress, Third ${ }^{\text {th }}$ edn, Handbook of Plant and Crop Stress. Taylor and Francis, Florida, USA, pp 901-942

Sio-Se Mardeh A, Ahmadi A, Poustini K, Mohammadi V (2006) Evaluation of drought resistance indices under various environmental conditions. Field Crop Res. 98: 222-229.

Sun L, Zhang J, Lu X, Zhang L, Zhang Y (2011) Evaluation to the antioxidant activity of total flavonoids extract from persimmon (Diospyros kaki L.) leaves. Food Chem Toxicol. 49(10): 26892696.

Temnykh S, DeClerck G, Lukashova A, Lipovich L, Cartinhour S, McCouch S (2001) Computational and experimental analysis of microsatellites in rice (Oryza sativa L.): frequency, length variation, transposon associations, and genetic marker potential. Genome Res. 11(8): 1441-1452.

Waziri A, Kumar P; Purty RS (2016) Saltol QTL and their role in salinity tolerance in rice. Austin J Biotechnol Bioeng. 3: 10671072.

Wenkert W, Lemon ER, Sinclair TR (1978) Leaf elongation and turgor pressure in field-grown soybean. Agron J. 70(5): 761-764.

Wu H, Shabala L, Liu X, Azzarello E, Zhou M, Pandolfi C, Shabala S (2015) Linking salinity stress tolerance with tissue-specific $\mathrm{Na}+$ sequestration in wheat roots. Front Plant Sci. 6.

Xu FF, Liang JIN, Huang Y, Chuan T., Chen YL, Bao JS (2016) Association mapping of quantitative trait loci for yield-related agronomic traits in rice (Oryza sativa L.). J Integr Agr. 15(10): 2192-2202.

Yan W, Rajcan I (2002) Biplot analysis of test sites and trait relations of soybean in ontario. Crop Sci. 42(1): 11-20.

Yang W, Guo Z, Huang C, Duan L, Chen G, Jiang N, Wang G (2014) Combining high-throughput phenotyping and genome-wide association studies to reveal natural genetic variation in rice. Nat. Commun. 5.

Yeo BPH, Bhave M, San Hwang S (2018) Effects of acute salt stress on modulation of gene expression in a Malaysian salt-tolerant indigenous rice variety, Bajong. J. Plant Res. 131(1): 191-202.

Zeng L, Shannon MC (2000) Salinity effects on seedling growth and yield components of rice. Crop Sci. 40: 996-1003.

Zeng L; Shannon MC; Lesch SM (2001) Timing of salinity stress affects rice growth and yield components. Agric Water Manage. 48: 191-206.

Zhu M, Zhou M, Shabala L, Shabala S (2017) Physiological and molecular mechanisms mediating xylem $\mathrm{Na}^{+}$loading in barley in the context of salinity stress tolerance. Plant Cell Environ. 40(7): 1009-102 